\title{
CONTO DE FADAS E DESENVOLVIMENTO DA CRIANÇA: UM ENSAIO
}

\section{ARTIGO ORIGINAL}

FREITAS, Tayline Levati de ${ }^{1}$

FREITAS, Tayline Levati de. Conto de fadas e desenvolvimento da criança: um ensaio. Revista Científica Multidisciplinar Núcleo do Conhecimento. Ano 06, Ed. 07, Vol. 02, pp. 101-113. Julho de 2021. ISSN: 2448-0959, Link de acesso: https://www.nucleodoconhecimento.com.br/educacao/conto-de-fadas, DOI: 10.32749/nucleodoconhecimento.com.br/educacao/conto-de-fadas

\section{RESUMO}

Este artigo trata-se de um ensaio que versa sobre o estudo do desenvolvimento da criança sobre a literatura através do uso do conto de fadas. O objetivo do artigo é apresentar uma modalidade que se utilizada, consegue auxiliar a criança no seu desenvolvimento. A metodologia utilizada foi pesquisas em base de dados, como o Google acadêmico, selecionando artigos para o desenvolvimento. O presente estudo especificará o que é um conto de fadas, incluindo suas origens e características, e em um segundo momentos, iremos trazer o conto de fadas sob o olhar da psicanálise e sua importância, relacionando com as diretrizes da educação brasileira MEC. Sendo possível observar que a leitura na vida da criança serve como um processo que ajuda a desenvolver linguagens, habilidades de atenção e escuta, trabalhando assim sua criatividade e imaginação.

Palavras-Chaves: Literatura, Conto de Fadas, Psicanálise.

\footnotetext{
${ }^{1}$ Pós-graduação em Urgência e Emergência. Graduação em Enfermagem. Cursando Licenciatura em Pedagogia. 


\section{INTRODUÇÃO}

Não é de hoje que se ouve falar sobre os contos de fadas, histórias cheias de magia e personagens que não existem na realidade, mas que muitos ficam apaixonados pelos enredos, histórias e finais felizes, o conto de fadas tende a ser pensado de uma maneira lúdica, entretanto esses mesmos contos podem ser um meio de desenvolvimento da oralidade, escrita, atenção, sequência lógica entre outros aspectos na criança.

Mas o que não se sabe é que essa modalidade de narrativa pode auxiliar a criança no seu desenvolvimento, aprendendo a encarar seus medos, angústias e inseguranças, podendo ajudá-la a resolver conflitos, os quais pode ser muito doloroso para a criança naquele momento.

Percebe-se que era um assunto pouco estudado nos meios educacionais, evidenciado pela dificuldade de encontrar textos e estudos sobre o assunto e que vem ganhando seu espaço, pois ao passar dos anos foi destacado a importância do tema na vida cotidiana da criança em pleno desenvolvimento, como menciona Bettelheim (2015, p. 13), sobre o conto de fadas "desabrocha e encorajam o seu desenvolvimento, ao mesmo tempo em que aliviam pressões pré-conscientes e inconscientes". Ainda existem poucos estudos na área da educação, sendo mais comum estudos na área psicologia e psicanálise.

O objetivo deste artigo é de conhecer o desenvolvimento da criança em seu cotidiano utilizando como meio a literatura especificamente o conto de fadas, relacionando um olhar psicanalítico e as diretrizes do ministério da educação para o tema.

Em um primeiro momento irá ser analisada sua origem, passando pelos primeiros contos e como foi alcançado as concepções das histórias atuais e suas características na literatura e cânone literário, ou seja, o que caracteriza um conto de fadas. 
No segundo capítulo irá ser discutido sobre a relação do conto de fadas do desenvolvimento da criança sob um olhar psicanalítico, trazendo os principais estudiosos sobre o assunto.

E por fim, serão analisadas as diretrizes do Ministério da Educação sobre o tema, fazendo a relação entre o psicanalítico e a educação.

\section{HISTÓRIA DOS CONTOS DE FADAS}

Conto de fadas no seu sentido literal nada mais é que histórias para crianças, uma narrativa que apresenta como personagens bruxas, fadas, ogros, trolls entre outros personagens imaginários envolvendo encantamentos e magia.

Normalmente temos como conto de fadas histórias para crianças, mas muitos adultos são encantados por esse ramo da literatura envolvente e atraente para as crianças (RAMOS, 2011).

\subsection{ORIGEM}

A concepção de infância foi constituída a pouco tempo, ou seja, elas eram consideradas adultos em miniatura a descoberta de que existia uma infância a ser considerada é muito recente (ALMEIDA, 2010).

O estudo de Almeida (2010), se refere aos anos anteriores à descoberta da concepção de infância, falava-se pouco sobre histórias infantis, elas eram escritas para adultos onde utilizavam uma narrativa cheia de violência, maus tratos, adultério, canibalismo, entre outros e eram contadas por narradores profissionais que recebiam essa profissão ainda jovens.

A partir dessa descoberta de concepção de infância, os contos de fadas foram adaptados para a nova realidade, contemplando o imaginário da criança.

Os primeiros relatos de uma coletânea de contos de fadas estão registrados na época de XVII, e foram considerados clássicos da literatura mundial cujo autor de chamava 
Charles Perrault, afinal quem já ouviu falar de histórias como Patinho Feio, A Bela Adormecida entre outros clássicos que vivem até hoje na literatura mundial (FERNANDES, 2019).

O momento do surgimento dos contos de fadas, que todos conhecem acontecia concomitantemente a Revolução Industrial junto com a Igreja que passavam pela contrarreforma. Onde naquela época os contos tinham uma característica vitoriana, a qual mostrava uma sociedade repressiva quanto às questões que envolvia sexualidade, e os conceitos de infância mostrado anteriormente e educação já estavam vigentes (SCHNEIDER, 2009).

Os contos eram como artifício para as governantas, amas e cuidadoras da época, utilizando dele para fascinar as crianças com histórias de monstros, fadas e bruxas (SCHNEIDER, 2009).

Segundo palavras de Machado (2010, p. 7), essas histórias milenares "eram de origem europeia e fazem parte desse inesgotável baú de tesouros que agrupamos sob o título genérico de "conto de fadas"'.

Apesar dos traços europeus que se pode encontrar nos contos de fadas, o seu surgimento acaba se confundindo com o surgimento da literatura infantil, pois são dois seguimentos que surgiram do folclore, tradições e cultura oral de povos antepassados.

Outros autores que deixaram sua marca na história da literatura são os irmãos Grimm, que se dedicaram a escrever fábulas infantis ganhando seu espaço ao longo do tempo, ambos foram acadêmicos, linguísticos, poetas e escritores. Nasceram na Alemanha no condado de Hesse-Darmstadt. Suas principais histórias foram Chapeuzinho Vermelho, Rapunzel, Branca de Neve, O Príncipe Sapo, João e Maria e Cinderela e "suas primeiras fábulas foram escritas entre 1812 e 1815" (VOLOBUEF, 2007, p. 1). Provavelmente essas histórias fazem parte da infância dos adultos de hoje.

De maneira sucinta os contos de fadas surgiram através da tradição oral de povos antepassados, os quais, não eram histórias para crianças, pois naquela época ainda 
criança eram consideradas adultos em miniaturas. Com o surgimento do conceito de infância buscou-se a adaptação dos textos ao desenvolvimento dos pequenos leitores e surgindo os contos como conhecemos hoje, cheio de aventura, imaginação e como consequência trazendo uma ideia unilateral sobre o assunto pois muitos acreditam que mostrando apenas um lado da realidade as crianças estão protegidas, esquecendo que a vida real não é apenas coisas boas, a criança vai se frustrar em vários momentos da vida sendo importante prepará-las.

Bettelheim (2015), comenta sobre as histórias modernas, que evitam os problemas existentes. Esses problemas são simulações do que a criança vai passar e enfrentar durante a vida e ela precisa que seja dada sugestões de como ela pode lidar com essas questões, tudo isso de forma simbólica trazendo o confronto com as necessidades humanas.

\subsection{CARACTERÍSTICAS DA LITERATURA}

O conto de fadas se caracteriza por ser textos narrativos com presença de seres místicos sejam eles sereias, fadas, bruxas, ogros, monstros entre outros. Normalmente são histórias curtas e narradas por um personagem que é considerado ramo da ficção, ou seja, histórias fictícias.

Os contos, em seu particular, não eram destinados ao mundo infantil, uma vez que as histórias eram abarrotadas de cenas de adultério, canibalismo, incesto, mortes hediondas e outros componentes do imaginário dos adultos (SCHNEIDER, 2009)

É notável como houve inúmeras alterações nos contos de fadas ao longo dos anos, hoje os contos são cheios de ternura, amor, mensagens de respeito, carinho e ensinamentos para a criança levar para a vida, pelo olhar da psicanálise contribui pouco ou nada para o desenvolvimento.

Bettelheim (2015) afirma que boa parte dos textos utilizados para leitura hoje no ambiente escolar são superficiais em substâncias que contribuem pouco para o 
desenvolvimento da criança, ou seja, "não consegue estimular e alimentar os recursos de que ela mais necessita para lidar com seus difíceis problemas íntimos".

Souza (2005), descreve os contos, como narrativas que contavam destinos de homens, dificuldades, sentimentos e relacionando com crenças sobrenaturais. Relatados por narradores profissionais que herdaram essa função de seus antecessores, como se fosse uma simples tradição.

Outra característica que os contos de fadas basicamente apresentam são a presença dos elementos que o compõe: o agressor (vilão), o doador (fada madrinha), o auxiliar (ajuda o herói), a princesa e a sua família (personagens centrais da história), o mandatário (pratica o crime) o herói (o que estabelece a paz) e o falso herói (tenta passar pelo herói) (SANTOS; GOMES, 2017).

Contudo certas características não têm uma regra definida sobre quem será vilão ou herói, como exemplo a história do chapeuzinho vermelho que traz uma mulher como heroína e o vilão em pele de lobo, assim as funções dos personagens estabelecem partes fundamentais do conto.

Prop (1928/1983), chegou a quatro teses fundamentais. 1) Os elementos constantes permanentes na história são as funções dos personagens, não importa quais sejam esses e como suas funções são implementadas, trazendo a função como parte básica do texto. 2) Essas funções possuem números limitados. 3) Suas sucessões são sempre idênticas. 4) Todos os contos possuem a mesma estrutura de escrita.

A narrativa que o conto de fadas utiliza como exemplo "Era uma vez...", "Num reino encantado...", "Num lugar não muito distante", traz características próprias ao texto, formando um enredo simples, preciso e rápido. Fazendo com que a criança perceba a existência de um tempo e não o que ela faz parte (DE FARIAS, 2012).

Tendo em vista o parágrafo acima, pode-se dizer que o importante em um conto de fadas é a sua estrutura de como acontece os fatos e não quem será o vilão ou a princesa, ou seja, o vilão pode ser um animal, um homem ou uma mulher e outros 
personagens que fazem parte da história também podem ser representados por animais ou gênero diferente do que conhecemos.

\section{CONTO DE FADAS E O DESENVOLVIMENTO DA CRIANÇA}

O conto de fadas é uma importante ferramenta na educação por estimular a curiosidade da criança, ajudará a criança a mostrar seus sentimentos de forma concreta e pode ser a construção de recursos imaginativos para poder lidar com a realidade, contribuindo para a formação do imaginário da criança.

Permitir que a criança ouça muitas histórias não contribuirá apenas para o interesse dela com a leitura, mas também com o processo de aprendizagem inicial, podendo brincar com os "mistérios da vida", sem se preocupar com a aprovação do adulto (DE FARIAS, 2012).

Segundo Bettelheim (2015, p. 10), à medida que a criança se desenvolve ela deve ser capaz de aprender a se entender melhor em consequência desse fato ela deve ser capaz de entender melhor os outros ao seu redor, podendo se relacionar de forma satisfatória e significativa.

A partir do momento que a criança consegue entender a si ela também consegue entender o próximo, ou seja, a criança deve encontrar o seu sentido na vida.

\subsection{CONTO DE FADAS POR UM OLHAR PSICANALÍTICO}

Bettelheim (2015), afirma que a psicanálise é conhecida por tornar a vida mais fácil, mas seu fundador não pretendeu isso, criando a psicanálise com o objetivo de capacitar o homem a entender a natureza e as dificuldades da vida sem ser derrotado por ela.

Chauí (1984), afirma em seus estudos que o uso dos contos infantis é comum para o diagnóstico e tratamento de crianças e adultos na clínica psicanalítica contemporânea. 
Os contos infantis têm sido terapêuticos desde suas origens, explicando o fato de sua existência até atualmente. Sendo utilizado principalmente na medicina hindu, como terapia para pessoas com problemas mentais, sendo vivido como a formação da personalidade e evolução interna da mente por utilizar a mesma linguagem que o inconsciente (CHAUÍ, 1984).

Sendo assim os contos de fadas encorajam o desenvolvimento da criança aliviando suas questões pré-conscientes e inconscientes, mostrando questões interiores que inconscientemente a criança irá entender, ajudando-a a resolver conflitos internos.

A partir daqui que conto de fadas atingiu um valor enorme, oferecendo a imaginação na criança novas dimensões para resoluções de conflitos, ou seja, "sua forma e estrutura sugerem à criança imagens com as quais ela pode estruturar seus devaneios e com eles dar a melhor direção à sua vida" (BETTELHEIM, 2015, p. 14).

Podemos referir que o conto de fadas conversa com a identidade da criança de forma inconsciente ajudando-a a lidar com problemas internos de maneira lúdica.

Bettelheim (2015), menciona que as histórias modernas evitam trazer problemas do nosso dia a dia, que são questões muito importantes na nossa vida, já os contos de fadas trazendo essas questões traz sugestões de maneira simples e simbólica que resolvam esses conflitos.

Essas histórias modernas, não confrontam a criança com as necessidades humanas básicas, como exemplo a morte. Esses conflitos em histórias modernas não são levados em consideração não ajudando a criança a lidar com eles, ao contrário, o conto de fadas se dirige diretamente a esses dilemas, mostrando soluções.

O conto de fadas em sua essência mostra à criança os problemas humanos básicos que podem ser vivenciados por ela ou que esteja já vivenciando, cujo elas não conseguem se expressar de forma oral. A história molda o desejo para que a criança possa viver sem culpa, enfrentando os próprios conflitos com o objetivo de lidar melhor com experiências dolorosas (PEREIRA; LEMOS, 2013). 
Analisando a história de João e Maria sobre o olhar da psicanálise, um dos contos mais famosos dos irmãos Grimm, de maneira sucinta os irmãos filhos de um lenhador que são abandonados na floresta pela madrasta e o pai. Por terem pouca comida a madrasta convenceu o pai de abandoná-las na floresta para que o casal pudesse sobreviver. Sua primeira tentativa não foi bem-sucedida, as duas crianças encontraram o caminha de casa, na segunda tentativa os irmãos se perderam na mata, após dias andando encontraram uma casinha feita de pão, doces, e bolos, como estavam famintas foram logo devorando tudo até que a porta foi aberta e uma senhora muito idosa apareceu.

Chamou os irmãos para dentro oferecendo um grande banquete e uma cama confortável para descansarem, ao amanhecer a bruxa prendeu João para engordá-lo e Maria fazia os trabalhos da casa.

Maria muito esperta falou ao irmão para guardar um ossinho e como a bruxa tinha a visão muito ruim ele mostrava o ossinho como se fosse seu dedo, mostrando que não estava engordando, até que um dia a bruxa perdeu a paciência e ia comê-lo assim mesmo magrinho, pediu para que a Maria pegasse água para cozinhar João, mas antes ela tinha que assar o pão, então mandou a maria ver se o fogo estava quente 0 suficiente para assar o pão.

Maria falou a bruxa que não sabia como fazer, a bruxa já irritada foi mostrar como Maria tinha que fazer, então com um forte empurrão Maria jogou a bruxa dentro da fornalha, onde ela morreu queimada.

A história de João e Maria começa justamente com uma realidade, pais pobres que não conseguem prover alimento aos seus filhos. Que ao anoitecer discutem como poderão sair dessa difícil situação. A mãe representa a fonte de toda a alimentação da criança, por isso ela passa pela má, ou seja, as crianças interpretam que a mãe quer abandoná-las. O pai tem um papel apagado sem eficiência ao longo da história (BETTELHEIM, 2015), fazendo referência com a vida real, trazendo o início da vida da criança, quando a mãe é de toda a importância para a sua alimentação, tanto nos aspectos bons quanto nos ameaçadores. 
Na primeira vez João usa pedra para marcar o caminho, e conseguiram encontrar o caminho para a casa, já na segunda vez perdendo a habilidade de pensar claramente pela angústia de passar fome, ele só consegue pensar no alimento, utilizando o pão para marcar o caminho de volta.

Bettelheim (2015, p. 226), traz a representação do pão na história como a "cordasalva-vidas", ou seja, mostrando os efeitos limitadores e primitivos em uma criança pequena os quais ela se entrega ao medo.

Essa história "corporifica as angústias e as tarefas de aprendizagem da criança pequena" (BETTELHEIM, 2015, p. 226), ou seja, a criança precisa aprender que caso ela não se liberte do seio dos pais, elas serão forçadas a fazer isso e terão que fazer contra sua vontade.

A história de maneira geral a qual começa como João sendo o pensador e trazendo a inteligência para livrar dos problemas, perdeu esse pensamento durante a história, mostrando a verdadeira força de Maria, trazendo a confiança em si mesma, a paciência de esperar a hora certa para fazer as coisas acontecerem, trazendo seu amadurecimento ao longo do conto, consequentemente desenvolvendo sua personalidade aprendendo que ela pode e deve opinar durante as resoluções de problemas. Já João aprende a dar vez a irmã e a confiar nela e não ser impulsivo.

Está é a mensagem que os contos de fadas transmitem às crianças de diversas maneiras: lutar contra as dificuldades da vida é inevitável e faz parte da sobrevivência humana, mas se a pessoa não se intimidar e estiver determinada a enfrentar testes inesperados e muitas vezes injustos, irá dominar todos os obstáculos e eventualmente vencer as dificuldades impostas (BETTELHEIM, 2015).

\subsection{CONTO DE FADAS E A EDUCAÇÃO}

Levando em consideração que história a cultura de um povo e a escola tem a função de inserir essa criança na cultura, portando um dos recursos e instrumentos para tal imersão se dá por meio da literatura. O RCN (1998) da Educação Infantil diz que: 
Ter acesso à boa literatura é dispor de uma formação cultural que alimenta a imaginação e desperta o prazer pela leitura. A intenção de fazer com que as crianças, desde cedo, apreciem o momento de se sentar para ouvir histórias exige que o professor, como leitor preocupa-se em lê-la com interesse, criando um ambiente agradável e convidativo à escuta atenta, mobilizando a expectativa das crianças, permitindo que elas olhem o texto e as ilustrações enquanto a história é lida (RCN, 1998, p. 143).

É notável que o gosto pela leitura acontece desde muito cedo e está intimamente ligado aos estímulos que a criança recebe, os pais que já têm o hábito de ler contribuem para que seus filhos adquirirem o gosto pela literatura.

A BNCC (2018), mostra a experiência com literatura como estímulo para o desenvolvimento do gosto pela leitura, estimula a imaginação e a ampliação do conhecimento de mundo, acontecendo junto com o educador mediador das histórias, além de proporcionar a familiaridade com os livros, diferentes gêneros literários.

O Referencial Curricular Nacional para a Educação Infantil (RCN, 1998) traz a leitura e a importância dos livros para crianças ainda pequenas.

Escutar esses contos do início da aprendizagem colabora para que a criança seja um bom leitor, abrindo caminhos infinitos de descobertas e de compreensão do mundo que o cerca. Através dos contos a criança pode deixar a imaginação fluir espontaneamente levando a criança a ter curiosidade e futuramente usar desse artifício para a resolução de problemas. Abramovich (1999, p. 147) expressa:

É ouvindo histórias que se pode sentir (também) emoções importantes, como a tristeza, a raiva, a irritação, o bem-estar, o medo, a alegria, o pavor, a insegurança, a tranquilidade, e tantas outras mais, e viver profundamente tudo o que as narrativas provocam em quem as ouve - com toda a amplitude, significância e verdade que cada uma delas fez (ou não) brotar... Pois é ouvir, sentir e enxergar com os olhos do imaginário!

A citação acima evidencia a importância da leitura e dos livros na vida da criança, o qual possibilitará várias aventuras e desafios indo além de uma simples história. 
Na Base Nacional Curricular (1988), documento que faz parte da educação que visa estabelecer os conhecimentos essenciais aos estudantes, evidencia a leitura como facilitadora aprimorando a linguagem verbal.

No entanto, o interesse pela leitura não é uma coisa que surge e sim tem que ser trabalhada com a criança, desde cedo oferecendo livros contando histórias, deixando a criança manusear o livro para que ela consiga fazer a descoberta de novos horizontes. Esse momento envolve toda a família a importância de os pais sentarem juntos aos filhos formando a base para o interesse da leitura.

\section{CONSIDERAÇÕES FINAIS}

Como pode-se observar durante o estudo a origem do conto de fadas, não possui um lugar específico de surgimento, cada região tem seus contos que foram passados por pessoas que contavam as histórias em lugares disponíveis na época.

Mas em um primeiro momento essas histórias não eram consideradas contos infantis, pois na época as crianças ainda eram consideradas como adultos em miniatura. Só após a concepção de infância aparecer que surgiu contos específicos para o público infantil, originando outros e os que já existiam foram modificados.

Os contos de fadas possuem suas características específicas, como a estrutura do texto e a presença de personagens místicos.

Em relação a psicanálise os contos de fadas têm sido usados para terapia de adultos e crianças, explicando sua existência até atualmente. Trazendo mensagens positivas para as resoluções de problemas e conflitos internos, ajudando principalmente a criança de forma lúdica a enfrentar seus medos e dificuldades atuais ou que ainda irão acontecer.

As diretrizes do Ministério da Educação (MEC), não traz um capítulo específico para o conto de fadas, citando o conto de fadas em seus capítulos sobre literatura, trazendo a importância da leitura na vida da criança como ferramenta de desenvolvimento das 
linguagens, para que a criança desenvolva habilidades de atenção e escuta e trabalhe sua imaginação e criatividade.

\section{REFERÊNCIAS}

ABRAMOVICH, F. Literatura Infantil. 5 ed. São Paulo: Scipione, 2001.

ALMEIDA, S. de O. A INFLUÊNCIA DOS CONTOS DE FADA PARA O DESENVOLVIMENTO INFANTIL. Ensinar Mais, p. 287, 2019.

BETTELHEIM, B. A psicanálise dos contos de fadas. Editora Paz e Terra, 2015.

BRASIL. A Especificidade do Texto Literário. In: Parâmetros Curriculares Nacionais. Brasília: MEC/SEF, 1997. 92 p.

BRASIL. Ministério da Educação. Base Nacional Comum Curricular. Brasília, 2018.

BRASIL. Referencial Curricular Nacional para a Educação Infantil - Ministério da Educação e do Desporto. Secretaria de Educação Fundamental. Brasília: MEC/SEF, 1998. 3v.: il.

CHAUÍ, M. Contos de fadas e Psicanálise. Repressão sexual: essa nossa (des) conhecida, p. 32-54, 1984.

DE FARIAS, F. R. A.; RUBIO, J. de A. S. Literatura infantil: a contribuição dos contos de fadas para a construção do imaginário infantil. 2012.

FERNANDES, E. F. B. Relevância dos contos de fadas na construção da personalidade infantil de alunos de escolas municipais de educação infantil do Bairro San Martin Recife-PE. Repositorio de Tesis y Trabajos Finales UAA, 2019.

MACHADO, A. M. Um eterno encantamento (apresentação). In: Contos de fadas: de Perrault, Grimm, Andersen e outros. Rio de Janeiro: Zahar, 2010. 
PEREIRA, V. O. B.; LEMOS, M. F. A função terapêutica dos contos de fadas: sentimentos e conflitos humanos. Perspectivas em Psicologia, v. 17, n. 2, 2013.

PROPP, V. Morfologia do conto. Lisboa: Vega. (1983).

RAMOS, D. I. L. História da literatura infantil na Madeira: reflexos de um mundo em mudança. 2011. Tese de Doutorado.

SANTOS, W.; GOMES, C. M. LEITURA DOS CONTOS DE FADAS: UMA PRÁTICA DE REESCRITA. Ensino de Língua e Literatura, p. 107.

SCHNEIDER, R. E. F.; TOROSSIAN, S. D. Contos de fadas: de sua origem à clínica contemporânea. Psicologia em revista, v. 15, n. 2, p. 132-148, 2009.

SOUZA, M. T. C. C. de et al. Relações entre aspectos afetivos e cognitivos em representações de contos de fadas. Boletim de psicologia, v. 58, n. 129, p. 227-242, 2008.

VOLOBUEF, K. Os Irmãos Grimm e a coleta de contos populares de língua portuguesa. XI Encontro Regional da Associação Brasileira de Literatura Comparada-Literatura, Artes, Saberes, 2007.

Enviado: Janeiro, 2021.

Aprovado: Julho, 2021. 